\title{
On the Connotation and Form of Toad in Folk Paper- Cut Art
}

\author{
Xun Yuan \\ School of Fine Arts \\ Huanggang Normal University \\ Huanggang, Hubei, China
}

\begin{abstract}
Toad shape has a rich form of expressions in Chinese folk art of paper-cut. As a traditional symbol of the subject, its application surface is very extensive. Toad shape shown by the aesthetic characteristics of a tendency to avoid harm and pursuit good luck and it is a kind of spiritual conversion into materialized. With a change of style after thousands of years, now it has been deeply rooted in the traditions among ethnic folk. Chinese folk paper-cut art with its unique charm styling vocabulary left us a distinctive style of shapes, and formed an important formation include lucky, praying, praying for child and so on.
\end{abstract}

Keywords-folk paper-cut; toad motif; symbol; form and connotation

\section{INTRODUCTION}

In the men farming and women weave Chinese ancient society, the invention of scissors is related with sewing, this time is around the Warring States period; the invention of paper is in Han Dynasty and become popular in Northern and Southern Dynasties. Therefore, the two basic tools for papercut are ready, and the folk art of paper-cutting appears about 1,600 years ago. Scholars create literati art with his writing brush, folk women create paper cutting and embroidery sewing with their sewing tools - scissors and needlework; the former is good at styling, the latter is good at the color. As the unique art form, folk paper-cut is a combination of material culture and spiritual culture of working women in order to meet their social needs, and it is a "living fossil." To be different with elite art, it is a part of people's folk life, it is an art, but it is also life, showing the working people and the natural love of life, it is Intangible Cultural indispensable carrier with folk customs and traditions.

The toad in the Chinese folk art is an important motif. Around this artistic symbol we have accumulated a wealth of modeling styles and rich symbolic meaning, and it is closely connected with Chinese concept of yin and yang and universe concept. In the meaning scopes, it not only expressed the concern about the auspicious things, the positive forms of life, but also in the hands of people yearning for a better life in the future. Based on the analysis of connotation of toad symbol in folk paper-cut, this article try to reveal this art form Lucky, praying, praying for child and other symbolic meanings.

\section{TOAD WORSHIP: THE SPIRIT ANIMAL OF TRADITIONAL FOLK ART}

Auspicious and spirit animal creation is always the pursuit of Chinese ancient culture, this culture character always exist in the "great tradition", and "little tradition" cultural context, and exudes a distant and mysterious atmosphere. Toad, as common folk art auspicious image, appears frequently from the late primitive society. As early as the Neolithic period, toad is one of the four tribal totems together with bird, fish and deer. Frog image has been found all over sites of the Yellow River Basin and Yangshao culture. The Neolithic Yangshao culture in Shanxi Banpo area six or seven thousand years ago and Gansu Majiayao culture period, the pottery of depicted in "frog pattern" had intriguing.

Since then, later in the various historical periods, toad has been appeared in various fields frequently. From bronze in Shang and Zhou dynasties, to the tomb murals, painting on silk, brick portrait, bronze mirrors and other artifacts in Qin and Han dynasties, a variety of different image patterns of frogs and toads toad and frog images have been portrayed. Toad guard on Zhang Heng seismograph in Eastern Han Dynasty, also in Huo Qubing's tomb, there is toad guard the gate. In the field of literature and oral folk tale, there are a lot of myths and legends about the toad. The most familiar example include: The goddess patching the sky, pluck cinnamon flowers in the palace of the moon, "Liu plays golden toad" and so on.

Many folk art - especially those from remote areas which is inconvenient communicate with outside world, those fold art form has a strong original nature. We found that today still many folk art heritage a certain degree of mankind's most original artistic impulses and thinking characteristics, and remains at the bottom of the riverbed of thousands of years of cultural evolution, which become a cultural sediment combination of form and meaning.

The reason why toads in early society is to be respected as clan totem worship, and gradually evolved into auspicious fetish, is due to human ignorance in the original period, social productivity is low, people had a tremendous sense of fear and reverence when they face of the mystery of human life objective material world. In cultural policy witchcraft produced a concept of animism. Thus, toad's living habits, life processes, morphological characteristics are projected in different meanings. Production and reproduction of the human 
race itself has always been a top priority, which lead to a connection with powerful toad fecundity. And various legends and myths of primitive religion makes toad is more of mystery. So in order to express the hope of a better life and sustenance, toad-related myths has also become an important subject in Folk Art.

\section{GOOD FORTUNE: TOAD CONNOTATION IN THE FORM OF PAPER-CUT ART}

System program of folk art is the creation under the long process of development arising from the collective and historic. Therefore, we can say the stylized art of language marks the maturity of Chinese paper-cut folk art. "Shape must have meaning, meaning must be lucky", it is mature characterization. And as mature art form there must be convention motif, and also a symbol of life and emotion category closely related phenomena. Whenever Humanities elite art, religious art, folk art takes no exception. Cultural context of the art of paper cutting has been deeply fit with the folk spiritual pursuit. As the most popular art form of folk art activities, not only ancient paper-cut artists to create a rich visual vocabulary, but also gives the paper-cut rich and profound meanings.

Toad symbol as an important symbol of paper-cut is to rely on the system to its heritage program. There are numerous and diverse toad shapes in paper-cut, but they carried the blessing and longing for generations, which has a sense of communication on the connotation.

\section{A. Symbols of Wealth and Fortune}

The concept of yin and yang is not only the summary on explain the movement of the universe by ancient Chinese, it also one of the origin symbols of their cultural creation activities. The mutual promotion and restraint on metal, wood, water, fire and earth affects people's cultural awareness, this tradition is an important civil context. "Historical Records Official Book" writes: "moon, yin of the heaven and earth, god of gold." "Han Shu, Liyue Zhi" writs "Moon waves a golden wave." Cultural logic here is: moon belongs with Yin and it called Tai yin. Yin reflects water, and in the Five Elements theory, water produce gold, so naturally moon has golden wave. Toad although looks ugly, but often out of their habits overnight, born in the water, so toad belongs with Yin and water, and then the moon toad will be golden toad.

Gold and silver are natural currency. Gold means wealth, pursuit of a wealthy life is human nature. Golden Toad as spirit animal, shown trillion wealth, "Golden toad" and "money" pronounce homophonic in China, so naturally became a symbol of wealth. Ancient auspicious words said: "Families with golden toad, then families with great wealth," can be seen as a straightforward expression of this psychology. Many folk art forms also save a lot of "Liu Hai plays golden toad", "Liu Hai throw money" symbolic motif, in the paper-cut this content is also very common: Toad has coin in its mouth , symbolizing produce money; there is a paper-cut called "Liu Hai throw money" "Fig. 1", or called "give money doll", it performance of the upper and lower levels 2 hand in hand dolls took the money, or Liu Hai bangs his hands a bunch of money, threw them to a three feet golden toad. As a symbol of prayer, it is easy to see the meaning of these paper-cut surplus people, a good harvest and a wealthy life. Here, the golden toad in paper-cut evolved into a symbol of the god of wealth.

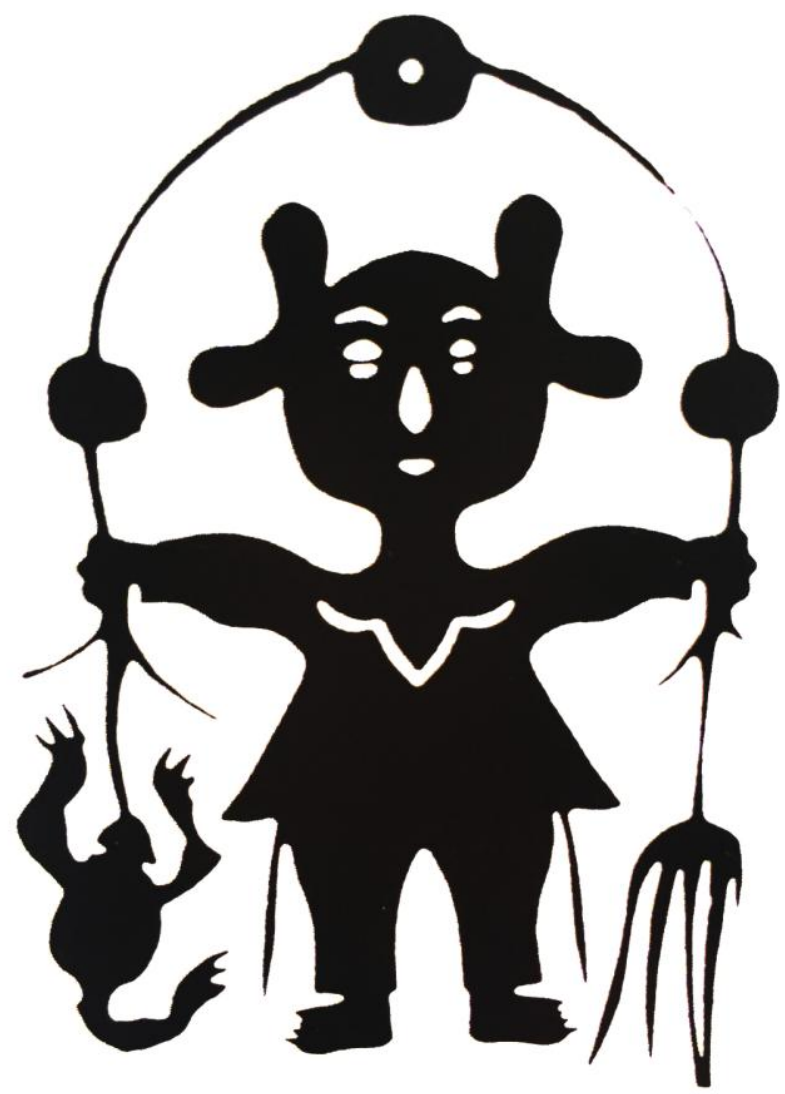

Fig. 1. "Liu Hai Throw Golden Toad"

\section{B. The Symbol of Fertility Worship}

"Fertility Worship" theme in folk paper-cut is very common. In traditional agrarian society, productivity is low, so create population is an important factor for wealth, the amount of the population is directly connected to the amount of wealth. Since ancient times, Chinese is longing for many children, a flourishing population, health and longevity, and this is reflection of this attitude. So as the family is concerned, multiply children become a top priority for daily worship and prayer. Descendants became the continuation of the eternal theme of folk paper-cut to be expressed. In fact, there are two meanings of this eternal theme, fertility worship and many descendants. The former is a mysterious phenomenon of life attitude, while the latter is a simply pursuit, both meanings has a natural combination in toad this mysterious creature.

Our myths and legends of the "Goddess Nv Wa" grip the dirt to made man, it is considered to be the ancestor of man, respect as the fertility God. In ancient Chinese speech, "Wa", "Frog" and "Baby" sound similar. Naturally, frog has been considered as an auspicious totem in the uncivilized period and people got to worship and sacrifice. Now this idea is still an important content in Shanxi paper-cut. In northern part of Shaanxi province and eastern part of Gansu area is also widely 
spread person frog laminated paper-cut patterns, the composition is in the form of pursuit" human frog consistency, descendants multiply," . In today's Shanxi province Yanchuan rural area, people will stick in the kiln door and window frames the big red frog shape cut the fertility God called "Zhuaji doll" "Fig. 2", the main image is the doll holds fish by hands, and applies plump flowers. For thousands of years, this graphic has been used as protection of God and the god of fertility of future generations of the Chinese nation, and guard the Yellow River Basin.

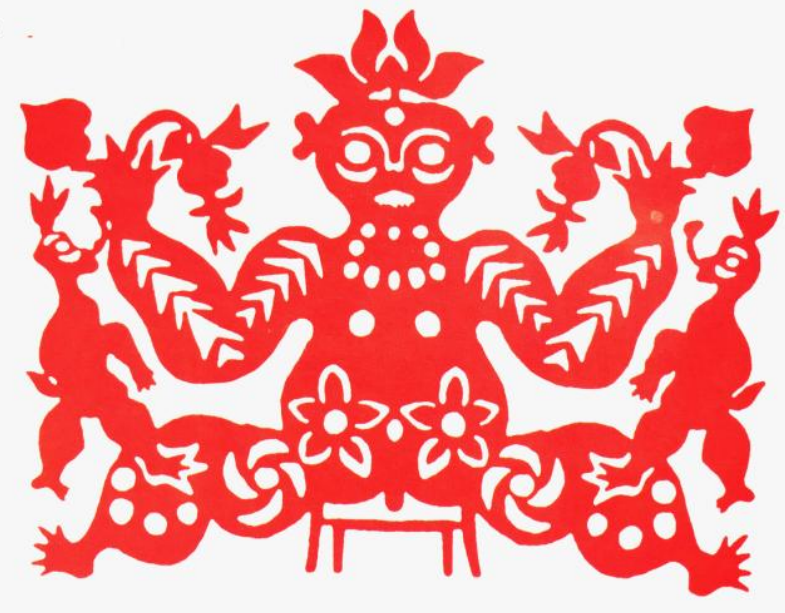

Fig. 2. "Zhuaji Doll”

In folk paper-cut , "chicken" and "toad" is often a symbol of men and women, "chicken play with toad" and "Liu Hai play with golden toad" shape combination is vaguely implies love story, "Chicken" and "Toad" always refer to men and women "play", Unmentionable love story has been expressed wisely by the combination of yin and yang. Such paper-cut is not just an expression for future generations and an endless life, but also is multiply deductive philosophy symbol.

In the Guanzhong Rural marriage custom, there usually will be a "Snake Enwinding Rabbit" paper-cut, this form sometimes adorned with a toad. Together, these form gives a sense of celebration, also symbolizes good luck and a happy life.

\section{The Symbol of Pursuing Good Luck and Avoiding Harm}

Symbolism of folk art depends on collective folk culture, and inheritance. Unlike personal Expression Paradigm elite art, they use established form code, repeatedly use metaphor, simile, synecdoche, metonymy, and other techniques, such forms to create a stable symbol category after repeatedly deductive process in the historic and cultural development.

Analysis of the country folk art, creators are mostly living at the bottom of the society, although their social and living environment is very poor, but they showed a strong desire for happiness and good fortune. They will pursue this simple hope in the creation of paper-cut and they give paper-cut shape imparting profound figurative meanings. The aesthetic characteristics of toad in paper-cut art exhibited by having good faith utilitarian tendency, people use paper-cut to express their primitive awareness of reproductive and life.

Toad shape image has a variety of forms of folk art, its roots come from constantly steeped in its own culture, and it is a typical non-material cultural patterns. In addition to the Lucky and praying for child meaning, toad in our traditional folk can fix illnesses and misfortunes, it can exorcise evil spirits, call for raining. In traditional folk theory, people called snakes, centipedes, scorpions, geckos and toads together as "Five Poisons." People think during May, around Dragon Boat Festival, "Five Poisons" will come out, this day is also known as "Five Poisons Day," or "Evil May." People will cut some of the "five poisons" paper-cut patterns, stick them on the wall to exorcise evil spirits and embroidery this "five poisons" pattern on the Chinese traditional belly-band for children in order to protect the children. (Fig. 3). In the private sector, usually after the confinement, women will put the "Five Poisons" pattern paper-cut on the quilt or under the pillow. Also there will be a plum petals decorated with "flower frog" paper-cut on the baby's pillow, even they will also carefully made a toad pillow for protecting from evil, bless the healthy growth of the new born child.

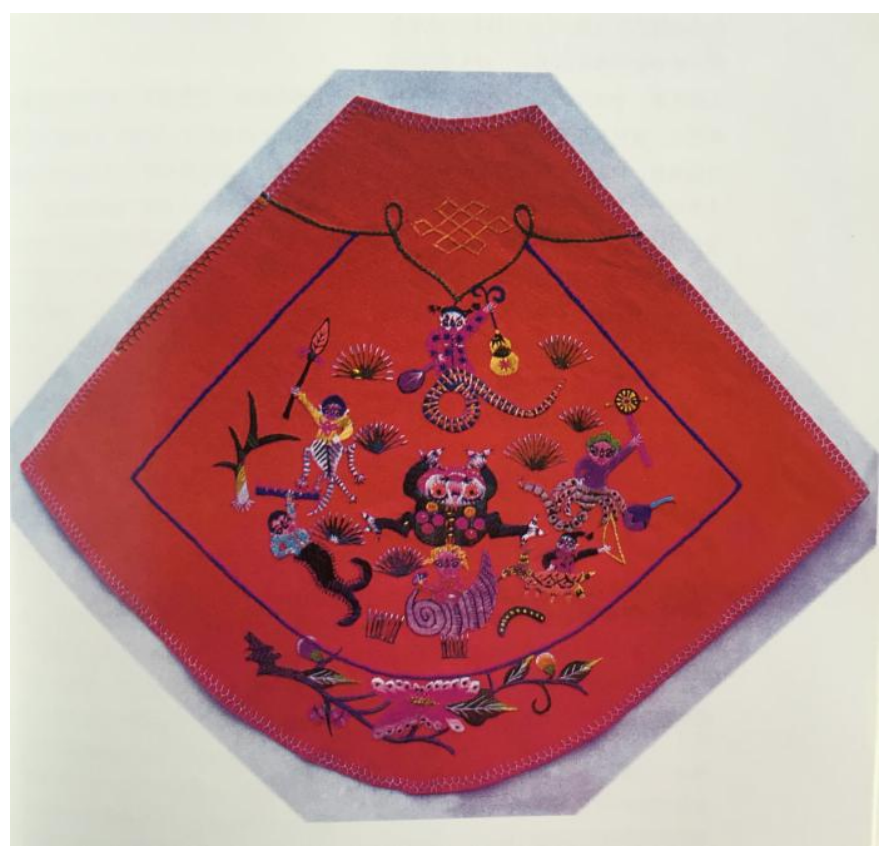

Fig. 3. "Five Poisons" belly-band

\section{CONCLUSION}

The symbolic feature of toad shape image in paper-cut art is created by our working people in the long process of labor practices. After thousands of years of development and changes, the emotion and faith of labor people has been expressed by means of the toad shapes, the toad shape and form of the connotation already deeply rooted in a long tradition of ethnic and folk custom, and it will give the art eternal vitality. 


\section{REFERENCES}

[1] Wang Guisheng: "Paper-cut Folk Cultural Interpretation", Beijing University Press, 2009.

[2] Jin Zhilin: "Zhuaji doll with human origin concept," Guilin Guangxi Normal University Press, 2001.

[3] Chen Jing: "Chinese folk paper-cut history", Beijing University Press, 2007.

[4] Wang Bomin: "Chinese folk paper-cut history", Hangzhou, China Academy of Fine Arts Publishing House, 2006. 